\title{
Using Illumina Infinium HumanMethylation 450K BeadChip to explore genome-wide DNA methylation profiles in a human hepatocellular carcinoma cell line
}

\author{
NING SUN, JIALIN ZHANG, CHENGSHUO ZHANG, YUE SHI, BOCHAO ZHAO, AO JIAO and BAOMIN CHEN \\ Department of Hepatobiliary and Transplantation Surgery, The First Affiliated Hospital of China Medical University, \\ Shenyang, Liaoning 110001, P.R. China
}

Received November 29, 2017; Accepted August 3, 2018

DOI: $10.3892 / \mathrm{mmr} .2018 .9441$

\begin{abstract}
Aberrant DNA methylation is the most common type of epigenetic alteration and is associated with many types of cancer. Although previous studies have provided a few novel DNA methylation markers in hepatocellular carcinoma (HCC), specific DNA methylation patterns and comparisons of the aberrant alterations in methylation between HCC and normal liver cell lines have not yet been reported. Therefore, in the present study the Illumina Infinium HumanMethylation 450K BeadChip was employed to identify the genome-wide aberrant DNA methylation profiles of Huh7 and L02 cells. Following Bonferroni adjustment, 102,254 differentially methylated CpG sites (covering 26,511 genes) were detected between Huh7 and L02 cells. Of those CpG sites, 62,702 (61.3\%) sites were hypermethylated (covering 12,665 genes) and 39,552 (38.7\%) sites were hypomethylated (covering 13,846 genes). The results of the present study indicated that $40.3 \%$ of the $\mathrm{CpG}$ sites were in $\mathrm{CpG}$ island regions, $20.7 \%$ were in $\mathrm{CpG}$ shores and $8.8 \%$ were in shelf regions. A total of $57.3 \%$ hypermethylated $\mathrm{CpG}$ sites and $39.4 \%$ of the hypomethylated $\mathrm{CpG}$ sites had a I $\beta$-Differencel $\geq 50 \%$. Within the significant differentially methylated $\mathrm{CpG}$ sites, 490 genes were located within 598 differentially methylated regions. Gene Ontology enrichment analysis revealed that 2,107 differentially methylated genes were associated with 'biological process', 13,351 differentially methylated genes were associated with 'molecular function', and 18,041 differentially
\end{abstract}

Correspondence to: Mr. Jialin Zhang, Department of Hepatobiliary and Transplantation Surgery, The First Affiliated Hospital of China Medical University, 155 Nanjing Street, Shenyang, Liaoning 110001, P.R. China

E-mail: jlz2000@yeah.net

Abbreviations: PLC, primary liver cancer; HCC, hepatocellular carcinoma; DMR, differentially methylated regions; GO, Gene Ontology

Key words: DNA methylation, genome-wide, hepatocellular carcinoma, BeadChip methylated genes were associated with 'cellular component'. Kyoto Encyclopedia of Genes and Genomes pathway-based analysis revealed 43 signaling pathways that were associated with 5,195 differentially methylated genes. These results demonstrated that aberrant DNA methylation may be a key and common event underlying the tumorigenesis of Huh7 cells. The present study also identified many subsets of hypo- or hyper-methylated $\mathrm{CpG}$ sites, genes and signaling pathways, which have an importance in the occurrence and development of HCC.

\section{Introduction}

Worldwide, primary liver cancer (PLC) is the second leading cause of cancer-associated mortality in poorly developed countries and the sixth in more developed countries (1). Of the $\sim 782,500$ new annual cases of PLC, China accounts for $>50 \%$ of the associated incidence (2). In 2015, PLC was the fourth most common type of cancer and the third most common cause of cancer-associated mortality in China (3). The majority of PLC cases occurring worldwide are cases of hepatocellular carcinoma (HCC) (1). Many risk factors can induce the development of $\mathrm{HCC}$, including chronic hepatitis B virus or hepatitis $\mathrm{C}$ virus infections, chronic alcoholic cirrhosis and high doses of aflatoxin B1 (4). Although a number of studies have identified a few of the molecular alterations associated with the pathogenesis of $\mathrm{HCC}$, the main mechanism underlying HCC is still unclear.

Previous studies have demonstrated that epigenetic alterations are one of the many early events that occur during tumorigenesis $(5,6)$. DNA methylation is the main epigenetic feature in regulating gene transcriptional regulation and preserving genome stability; however, aberrant DNA methylation can lead to the inactivation of tumor suppressor genes or activation of oncogenes, which eventually induces the development of many types of cancer $(7,8)$. A number of studies have also reported alterations in one or several genes at one time; the abnormal methylation of genes, including Ras association domain family member 1 (9), p16, postmeiotic segregation increased 2, MutL homolog 1, MutS homolog 2 (10), Adenomatosis polyposis coli (11) and glutathione S-transferase Pi $1(12,13)$, has also been 
associated with HCC. Shen et al (14) used Illumina Infinium HumanMethylation $27 \mathrm{~K}$ arrays to analyze $27,578 \mathrm{CpG}$ sites covering 14,495 genes in paired HCC tumor and adjacent non-tumor tissues. The Illumina Infinium HumanMethylation $450 \mathrm{~K}$ BeadChip represents a significant improvement in the detection of $\mathrm{CpG}$ sites (482,421 CpG and 3,091 non-CpG sites), covers $99 \%$ of RefSeq genes with multiple sites in annotated promoters $(1,500$ or $200 \mathrm{bp}$ upstream of the transcription start site), 5'-untranslated regions (UTRs), first exons, gene body, and 3'-UTRs (15). Previously, aberrant DNA hypermethylation of $\mathrm{CpG}$ islands was reported to induce the inactivation of tumor suppressor genes (16), which was thought to contribute to tumorigenesis (17). Recently, previous studies have revealed that cancer-associated aberrant DNA methylation not only occurs within $\mathrm{CpG}$ islands but may also be detected within CpG shores or $\mathrm{CpG}$ shelves (18-20).

To the best of our knowledge, no research analyzing the genome-wide DNA methylation status within a HCC cell line using the Illumina Infinium HumanMethylation $450 \mathrm{~K}$ BeadChip has been conducted. Therefore, in the present study, the Illumina 450K Methylation BeadChip was employed to screen promoter DNA methylation and the expression profiles of methylated genes in a human hepatocellular carcinoma cell line (Huh7 cells) and in a human normal liver cell line (L02 cells). The results may aid the characterization of differentially methylated $\mathrm{CpG}$ sites, regions and genes associated with the pathogenesis of HCC, thereby improving our current understanding of the methylation mechanisms underlying the development and progression of HCC.

\section{Materials and methods}

Cell culture. The human HCC cell line, Huh7 and the human normal liver cell line, L02, were purchased from the Cell Bank of Type Culture Collection of Chinese Academy of Sciences (Shanghai, China). Huh7 cells were maintained in Dulbecco's modified Eagle's medium (DMEM; Invitrogen; Thermo Fisher Scientific, Inc., Waltham, MA, USA), while L02 cells were maintained in RPMI-1640 (Invitrogen; Thermo Fisher Scientific, Inc.). The cell lines were supplemented with $100 \mathrm{U} / \mathrm{ml}$ penicillin and $100 \mathrm{~g} / \mathrm{ml}$ streptomycin in the presence of $10 \%$ fetal bovine serum (FBS; Gibco; Thermo Fisher Scientific, Inc.) and incubated in a humidified atmosphere containing $5 \% \mathrm{CO}_{2}$ at $37^{\circ} \mathrm{C}$.

DNA preparation and Illumina Infinium HumanMethylation $450 K$ BeadChip assay. DNA was extracted from the two cell lines (Huh7 and L02) using a QIAamp DNA Micro kit (Qiagen $\mathrm{GmbH}$, Hilden, Germany) according to the manufacturer's protocol. Bisulfite modification of $1 \mu \mathrm{g}$ DNA was conducted using an EZ DNA Methylation kit (Zymo Research Corp., Irvine, CA, USA) according to the manufacturer's protocol. The Illumina Infinium HumanMethylation 450K BeadChip assay was performed according to Illumina's standard protocol (Illumina, Inc., San Diego, CA, USA). Experiments with Huh7 and L02 cells were performed in triplicate to avoid false positive and false negative results.

Statistical analysis. The methylation data were processed with the Methylation Module of GenomeStudio software
(Methylation v1.9; Illumina, Inc.). The methylation levels of the $\mathrm{CpG}$ sites were calculated as $\beta$-values: $\beta=$ intensity of the methylated allele $(\mathrm{M}) /[$ intensity of the unmethylated allele (U) $+\mathrm{M}+100]$ (15). A t-test, in addition to analysis of variance with Bonferroni correction for multiple comparisons was used to compare differentially methylated $\mathrm{CpG}$ sites between Huh7 and L02 cells. The differentially methylated CpG sites were defined as sites with Adjusted P-values of $\leq 0.05$ and $\mid \beta$-Difference $\geq 0.2$. Methylation measures with a detection $\mathrm{P}>0.05$ and $\mathrm{CpG}$ coverage $<95 \%$ were excluded (14). For the selection of candidate $\mathrm{CpG}$ sites that had significant differences between Huh7 and L02 cell methylation levels, the following additional filtering criteria were applied: i) Adjusted $\mathrm{P} \leq 0.05$, which corresponds to a raw $\mathrm{P}$-value of $\leq 1.06 \times 10^{-7}$; ii) for significantly hypermethylated $\mathrm{CpG}$ sites, the $1 \beta$-Differencel in the methylation levels between Huh7 and L02 cells was $>20 \%$, and the mean methylation level for L02 was $<25 \%$; and iii) for significantly hypomethylated $\mathrm{CpG}$ sites, the methylation level $\mid \beta$-Differencel between L02 and Huh7 cells was $>20 \%$, and the mean methylation level for Huh7 cells was <25\% (14).

Functional annotation of differentially methylated genes. The genes for which the $\mathrm{CpG}$ sites corresponded with differential methylation levels were determined using Kyoto Encyclopedia of Genes and Genomes (KEGG) Pathway (www.genome. jp/kegg/) and Gene Ontology (GO; www.geneontology.org/) databases to analyze the pathway and enrichment information of these genes.

\section{Results}

Global DNA methylation in Huh7 and LO2 cells. Following a t-test with Bonferroni correction for multiple comparisons, 102,254 differentially methylated $\mathrm{CpG}$ sites (covering 26,511 genes) were detected between Huh7 and L02 cells. Within these $\mathrm{CpG}$ sites, 62,702 (61.3\%) sites were hypermethylated (covering 12,665 genes), and 39,552 (38.7\%) sites were hypomethylated (covering 13,846 genes). The results suggested that aberrant DNA methylation may a very common event in Huh7 cells, and alterations in hypermethylation were more frequently observed than hypomethylation. Figs. 1 and 2 present hierarchical cluster analysis of the differentially methylated $\mathrm{CpG}$ sites and genes that distinguish Huh7 from L02 cells.

In addition, the results revealed that there were 41,178 (40.3\%) $\mathrm{CpG}$ sites located in $\mathrm{CpG}$ island regions, 21,150 (20.7\%) CpG sites were within $\mathrm{CpG}$ shores, 9,030 (8.8\%) CpG sites were in shelves, and 30,896 (30.2\%) CpG sites were in open sea (Table I). Furthermore, the results also demonstrated that within different regions, the distribution of hypo- or hypermethylated $\mathrm{CpG}$ sites differed: In $\mathrm{CpG}$ island regions, $19,462(47.3 \%) \mathrm{CpG}$ sites were hypermethylated and 21,716 (52.7\%) CpG sites were hypomethylated. In CpG shore regions, 13,729 (64.9\%) CpG sites were hypermethylated and 7,421 (35.1\%) CpG sites were hypomethylated. In shelf regions, 7,340 (81.3\%) CpG sites were hypermethylated and 1,690 (18.7\%) CpG sites were hypomethylated.

Frequency distribution of differentially methylated $\mathrm{Cp} G$ sites between Huh7 and LO2 cells. In the results of the 


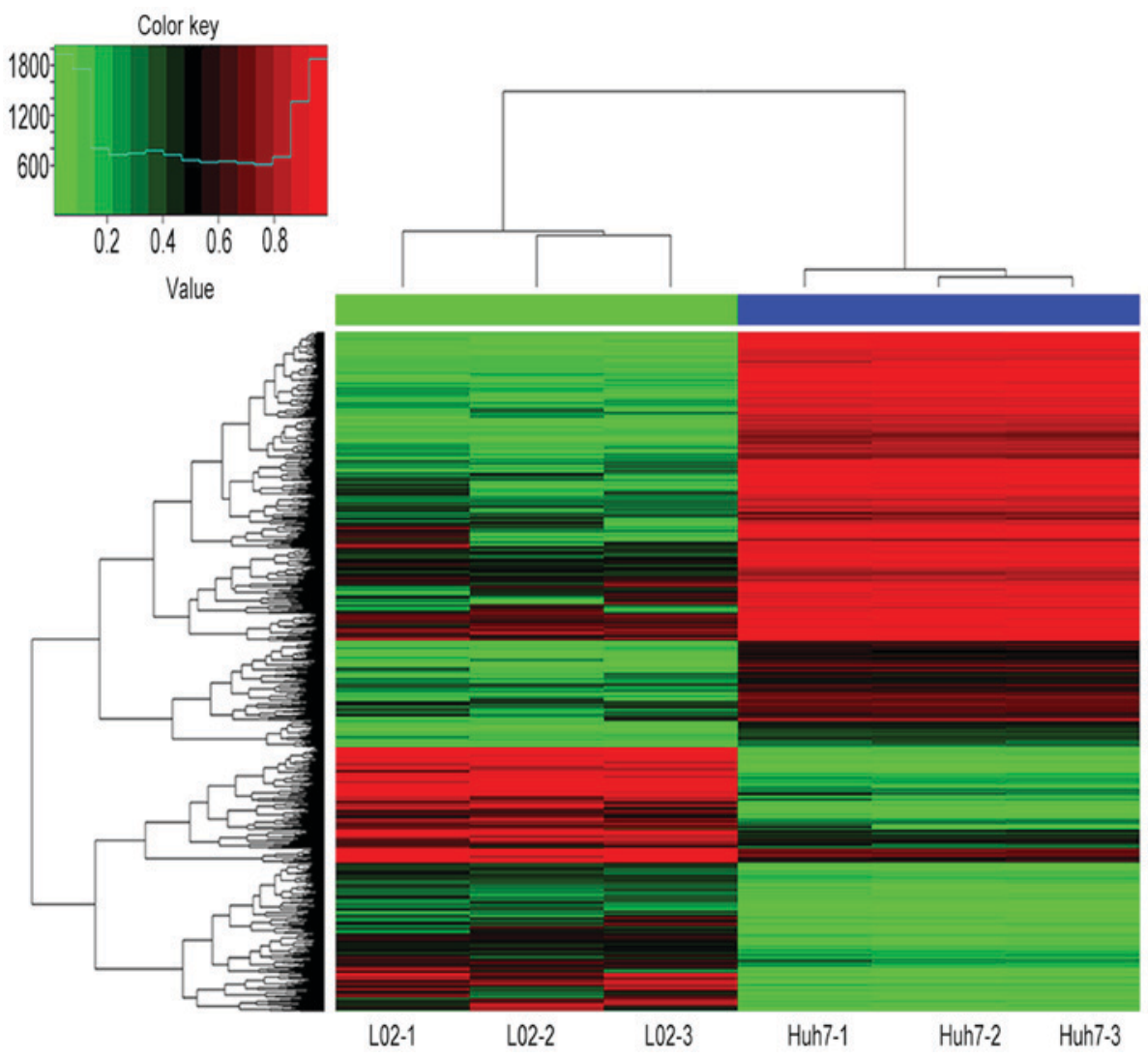

Figure 1. Hierarchical cluster analysis of all of the differentially methylated CpG sites between Huh7 and L02 cells.

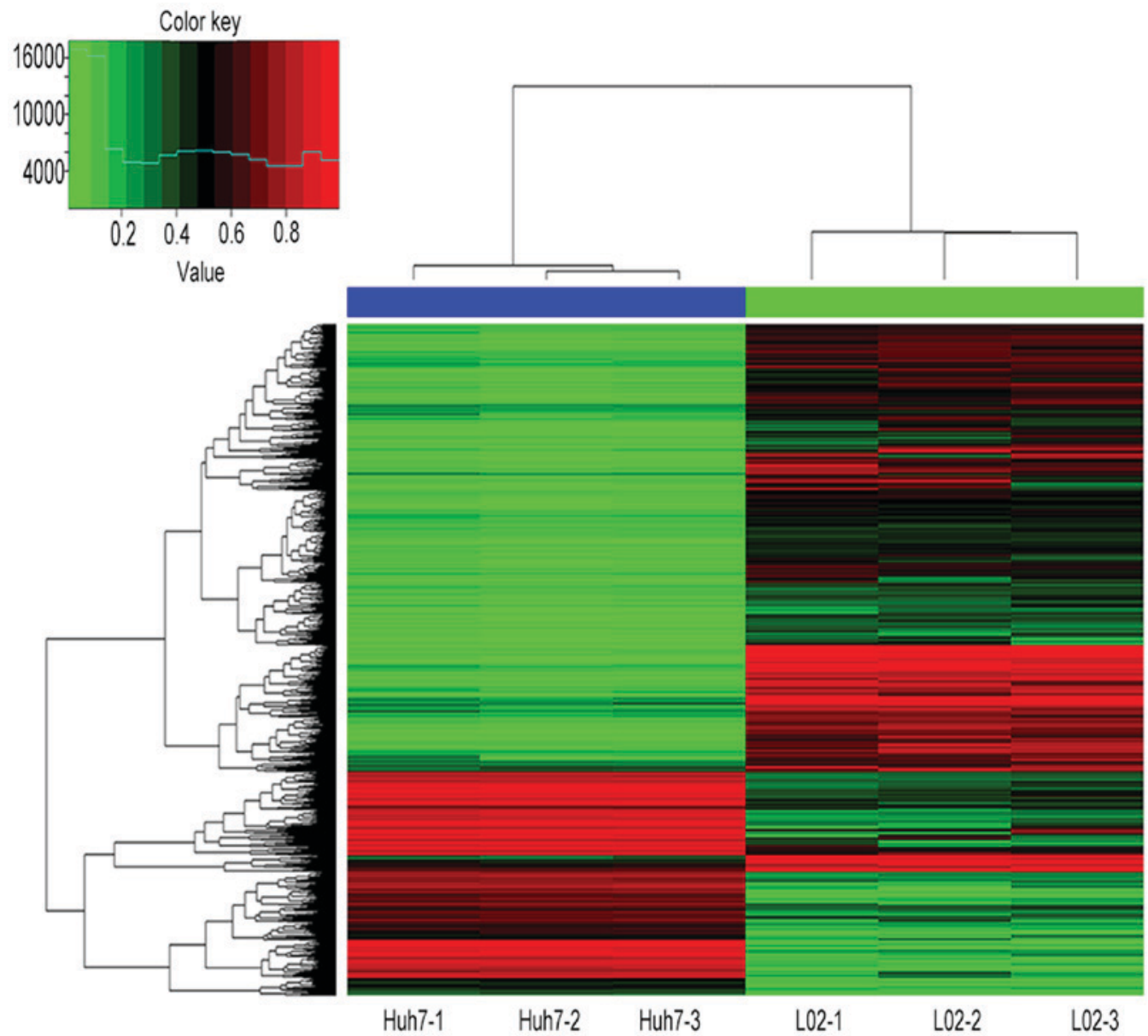

Figure 2. Hierarchical cluster analysis of all of the differentially methylated genes between Huh7 and L02 cells. 
Table I. Distribution of all of the differentially methylated CpG sites.

\begin{tabular}{lccc}
\hline Type & $\begin{array}{c}\text { All methylated } \\
\text { CpG sites, n (\%) }\end{array}$ & $\begin{array}{c}\text { Hypermethylated } \\
\text { CpG sites, n (\%) }\end{array}$ & $\begin{array}{c}\text { Hypomethylation } \\
\text { CpG sites, n }(\%)\end{array}$ \\
\hline CpG island & $41,178(40.3)$ & $19,462(47.3)$ & $21,716(52.7)$ \\
CpG shores & $21,150(20.7)$ & $13,729(64.9)$ & $7,421(35.1)$ \\
CpG shelves & $9,030(8.8)$ & $7,340(81.3)$ & $1,690(18.7)$ \\
Open sea & $30,896(30.2)$ & $22,171(71.8)$ & $8,725(28.2)$ \\
Total & 102,254 & 62,702 & 39,552 \\
\hline
\end{tabular}

Table II. Frequency distribution of all of the differentially methylated CpG sites in Huh7 and L02 cells by methylation status.

\begin{tabular}{|c|c|c|c|c|c|c|}
\hline $\begin{array}{l}\text { I } \beta \text {-differencel, } \\
\%\end{array}$ & $\begin{array}{l}\text { Hypermethylated } \\
\text { CpG sites, n (\%) }\end{array}$ & $\begin{array}{c}\text { Cumulative, } \\
\%\end{array}$ & $\begin{array}{l}\text { Hypomethylated } \\
\text { CpG sites, n (\%) }\end{array}$ & $\begin{array}{c}\text { Cumulative, } \\
\%\end{array}$ & $\begin{array}{l}\text { Total CpG } \\
\text { sites, n (\%) }\end{array}$ & $\begin{array}{c}\text { Cumulative, } \\
\%\end{array}$ \\
\hline$\geq 60$ & $25,585(40.8)$ & 40.8 & $10,796(27.3)$ & 27.3 & $36,381(35.6)$ & 35.6 \\
\hline $50 \leq x<60$ & $10,352(16.5)$ & 57.3 & $4,791(12.1)$ & 39.4 & $15,134(14.8)$ & 50.4 \\
\hline $40 \leq x<50$ & $9,681(15.4)$ & 72.7 & $6,159(15.6)$ & 54.0 & $15,840(15.5)$ & 65.9 \\
\hline $30 \leq x<40$ & $8,848(14.1)$ & 86.8 & $8,018(20.3)$ & 75.3 & $16,866(16.5)$ & 82.4 \\
\hline $20 \leq x<30$ & $8,236(13.1)$ & 100.0 & $9,788(24.7)$ & 100.0 & $18,024(17.6)$ & 100.0 \\
\hline Total & 62,702 & - & 39,552 & - & 102,254 & - \\
\hline
\end{tabular}

present study, 35,937 (57.3\%) hypermethylated $\mathrm{CpG}$ sites and $15,587(39.4 \%)$ hypomethylated $\mathrm{CpG}$ sites were observed to have an $\mid \beta$-Differencel $\geq 50 \%$. A total of $18,529(29.5 \%)$ of hypermethylated $\mathrm{CpG}$ sites and 14,177 (35.9\%) hypomethylated $\mathrm{CpG}$ sites had an $\mid \beta$-Differencel $\geq 30 \%$ but $<50 \%$. A total of 8,236 (13.1\%) hypermethylated $\mathrm{CpG}$ sites and 9,788 (24.7\%) of hypomethylated $\mathrm{CpG}$ sites had an $\mathrm{I} \beta$-Differencel $<30 \%$ but $\geq 20 \%$ (Table II). Collectively, these results revealed that DNA aberrant hypermethylation in Huh7 cells was more frequent than in L02 cells, which may serve a potential role in genomic instability.

Significant differentially methylated $C p G$ sites and genes. To reduce the potential impact of an extreme $\beta$ value on methylation differences, the present study applied stringent criteria to select potentially biologically important $\mathrm{CpG}$ sites (14). A total of 5,285 significantly hypermethylated $\mathrm{CpG}$ sites (covering 3,222 genes) and 2,659 significantly hypomethylated $\mathrm{CpG}$ sites (covering 2,204 genes) were observed. For the significantly hypermethylated $\mathrm{CpG}$ sites, there were 1,544 sites in CpG islands, 1,137 sites in $\mathrm{CpG}$ shores, 655 sites within $\mathrm{CpG}$ shelves and 1,949 sites in open sea regions. By contrast, for the significantly hypomethylated CpG sites, there were 1,201 sites in $\mathrm{CpG}$ islands, 632 sites in $\mathrm{CpG}$ shores, 133 sites in $\mathrm{CpG}$ shelves and 693 sites in open sea regions (Table III). The top 20 differentially hypermethylated and hypomethylated sites and genes are presented in the Tables IV and V.

Significant differentially methylated regions (DMRs). The results of the present study revealed that 390 significantly hypermethylated $\mathrm{CpG}$ sites (covering 287 genes) and 208 significantly hypomethylated $\mathrm{CpG}$ sites (covering 203 genes) were in DMRs. For the significantly hypermethylated
Table III. Distribution of genomic regions for significant differentially methylated $\mathrm{CpG}$ sites in Huh7 cells when compared with L02 cells.

\begin{tabular}{lcc}
\hline Type & $\begin{array}{r}\text { Hypermethylated } \\
\text { CpG sites, } n\end{array}$ & $\begin{array}{r}\text { Hypomethylated } \\
\text { CpG sites, } n\end{array}$ \\
\hline CpG island & 1,544 & 1,201 \\
CpG shores & 1,137 & 632 \\
CpG shelves & 655 & 133 \\
Open sea & 1,949 & 693 \\
Total & 5,285 & 2,659 \\
\hline
\end{tabular}

CpG sites, 64 sites were in cancer-specific (c)-DMRs, 125 sites were in reprogramming-specific (r)-DMRs and 201 sites were in DMRs; for the significantly hypomethylated $\mathrm{CpG}$ sites, 30 were located within cDMRs, 74 were located within rDMRs and 104 were located within DMRs (Table VI; Fig. 3).

GO enrichment and KEGG pathway analysis. GO enrichment and the KEGG Pathway database were employed to analyze information regarding the differentially methylated genes. The results of GO enrichment revealed that there were 2,107 differentially methylated genes associated with 'biological process', and the most enriched groups included negative regulators of cell proliferation, negative regulators of transcription such as RNA polymerase II promoter, and synaptic transmission. A total of 13,351 differentially methylated genes were associated with 'molecular function', and the most enriched groups included protein binding, DNA binding and metal ion binding. A total of 18,041 differentially methylated genes were 
Table IV. Top 20 significant hypermethylated CpG sites and genes within differentially methylated regions in Huh7 cells when compared with L02 cells.

\begin{tabular}{|c|c|c|c|c|c|}
\hline CpG sites & Adjust P-value & $\mid \beta$-differencel & Mean Huh & Mean L02 & Hypermethylated genes \\
\hline $\operatorname{cg} 11058366$ & $2.09 \times 10^{-6}$ & 0.924 & 0.934 & 0.010 & ERBB4 \\
\hline $\operatorname{cg} 13245152$ & $1.69 \times 10^{-6}$ & 0.863 & 0.876 & 0.013 & PAX6 \\
\hline $\operatorname{cg} 25758545$ & $1.69 \times 10^{-6}$ & 0.863 & 0.876 & 0.013 & SALL4 \\
\hline $\operatorname{cg} 14950829$ & $1.69 \times 10^{-6}$ & 0.925 & 0.940 & 0.015 & PCDH8 \\
\hline $\operatorname{cg} 09260089$ & $1.69 \times 10^{-6}$ & 0.952 & 0.968 & 0.016 & NKX6-2 \\
\hline $\operatorname{cg} 11459773$ & $1.69 \times 10^{-6}$ & 0.876 & 0.891 & 0.015 & BCL3 \\
\hline $\operatorname{cg} 12989574$ & $1.69 \times 10^{-6}$ & 0.965 & 0.983 & 0.018 & GPC6 \\
\hline $\operatorname{cg} 03129384$ & $1.69 \times 10^{-6}$ & 0.956 & 0.974 & 0.018 & FAM196A; DOCK1 \\
\hline $\operatorname{cg} 03396151$ & $1.69 \times 10^{-6}$ & 0.929 & 0.947 & 0.018 & MEIS2 \\
\hline $\operatorname{cg} 04556126$ & $1.69 \times 10^{-6}$ & 0.920 & 0.938 & 0.018 & $\mathrm{ZIC} 4$ \\
\hline $\operatorname{cg} 20317123$ & $1.69 \times 10^{-6}$ & 0.947 & 0.966 & 0.019 & TCF21 \\
\hline $\operatorname{cg} 21062760$ & $1.69 \times 10^{-6}$ & 0.876 & 0.894 & 0.018 & ZBTB32 \\
\hline $\operatorname{cg} 09454560$ & $1.99 \times 10^{-6}$ & 0.624 & 0.636 & 0.013 & LRFN2 \\
\hline $\operatorname{cg} 12090740$ & $1.69 \times 10^{-6}$ & 0.892 & 0.911 & 0.020 & BCL2 \\
\hline $\operatorname{cg} 24249411$ & $1.69 \times 10^{-6}$ & 0.887 & 0.907 & 0.020 & BDNF \\
\hline cg00057722 & $1.69 \times 10^{-6}$ & 0.929 & 0.950 & 0.021 & - \\
\hline $\operatorname{cg} 08640046$ & $1.69 \times 10^{-6}$ & 0.810 & 0.828 & 0.018 & - \\
\hline $\operatorname{cg} 03283124$ & $2.03 \times 10^{-6}$ & 0.898 & 0.920 & 0.021 & PCDH9 \\
\hline $\operatorname{cg} 13087076$ & $1.69 \times 10^{-6}$ & 0.890 & 0.912 & 0.021 & DYDC2 \\
\hline $\operatorname{cg} 25453154$ & $2.03 \times 10^{-6}$ & 0.820 & 0.839 & 0.020 & ZCCHC24 \\
\hline
\end{tabular}

Data are presented to 3 decimal places.

Table V. Top 20 significant hypomethylated CpG sites and genes within differentially methylated regions in Huh7 cells when compared with L02 cells.

\begin{tabular}{|c|c|c|c|c|c|}
\hline CpG sites & Adjust P-value & $\mid \beta$-differencel & Mean Huh & Mean L02 & Hypomethylated gene \\
\hline $\operatorname{cg} 10739344$ & $1.70 \times 10^{-6}$ & 0.894 & 0.019 & 0.913 & WDR76 \\
\hline cg00618865 & $1.69 \times 10^{-6}$ & 0.945 & 0.023 & 0.967 & PLXND1 \\
\hline $\operatorname{cg} 16267343$ & $1.69 \times 10^{-6}$ & 0.898 & 0.024 & 0.922 & NPR3 \\
\hline $\operatorname{cg} 00138041$ & $1.69 \times 10^{-6}$ & 0.943 & 0.029 & 0.972 & PRDM8 \\
\hline $\operatorname{cg} 01529365$ & $1.69 \times 10^{-6}$ & 0.930 & 0.031 & 0.961 & - \\
\hline cg09564253 & $1.69 \times 10^{-6}$ & 0.902 & 0.031 & 0.933 & LASP1 \\
\hline $\operatorname{cg} 08176368$ & $1.69 \times 10^{-6}$ & 0.926 & 0.033 & 0.959 & MMP9 \\
\hline $\operatorname{cg} 08812555$ & $2.05 \times 10^{-6}$ & 0.784 & 0.029 & 0.813 & DKK1 \\
\hline $\operatorname{cg} 25612391$ & $1.77 \times 10^{-6}$ & 0.741 & 0.028 & 0.769 & SLC25A42 \\
\hline $\operatorname{cg} 22417879$ & $1.70 \times 10^{-6}$ & 0.908 & 0.035 & 0.943 & SDCBP2 \\
\hline $\operatorname{cg} 15019790$ & $1.69 \times 10^{-6}$ & 0.924 & 0.036 & 0.960 & SIX2 \\
\hline $\operatorname{cg} 07407787$ & $1.69 \times 10^{-6}$ & 0.922 & 0.036 & 0.958 & ARSG; SLC16A6 \\
\hline $\operatorname{cg} 08361684$ & $1.69 \times 10^{-6}$ & 0.911 & 0.038 & 0.949 & FJX1 \\
\hline $\operatorname{cg} 16195157$ & $1.69 \times 10^{-6}$ & 0.900 & 0.038 & 0.938 & DNAJB1 \\
\hline $\operatorname{cg} 15842502$ & $1.69 \times 10^{-6}$ & 0.913 & 0.040 & 0.953 & RB 1 \\
\hline $\operatorname{cg} 13848566$ & $1.95 \times 10^{-6}$ & 0.934 & 0.041 & 0.975 & GAS1 \\
\hline $\operatorname{cg} 27454412$ & $1.81 \times 10^{-6}$ & 0.781 & 0.034 & 0.815 & C7orf50 \\
\hline $\operatorname{cg} 02152578$ & $1.69 \times 10^{-6}$ & 0.931 & 0.041 & 0.972 & AHCYL1 \\
\hline $\operatorname{cg} 13355248$ & $1.69 \times 10^{-6}$ & 0.792 & 0.038 & 0.829 & NPTX1 \\
\hline $\operatorname{cg} 16443866$ & $1.69 \times 10^{-6}$ & 0.878 & 0.042 & 0.920 & STC2 \\
\hline
\end{tabular}

Data are presented to 3 decimal places. 


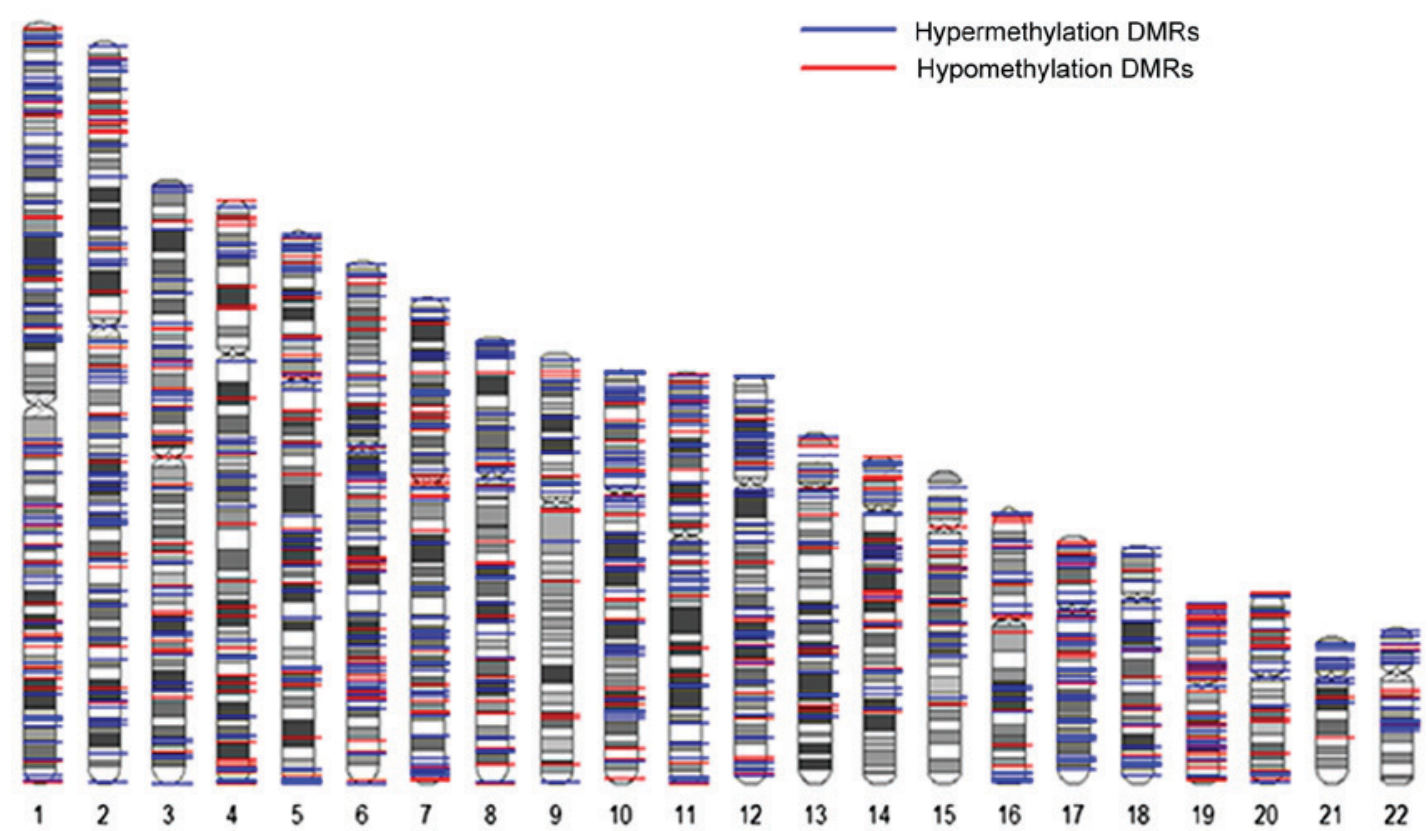

Figure 3. Significantly hypermethylated and hypomethylated genes located in DMRs. DMRs, differentially methylated regions.

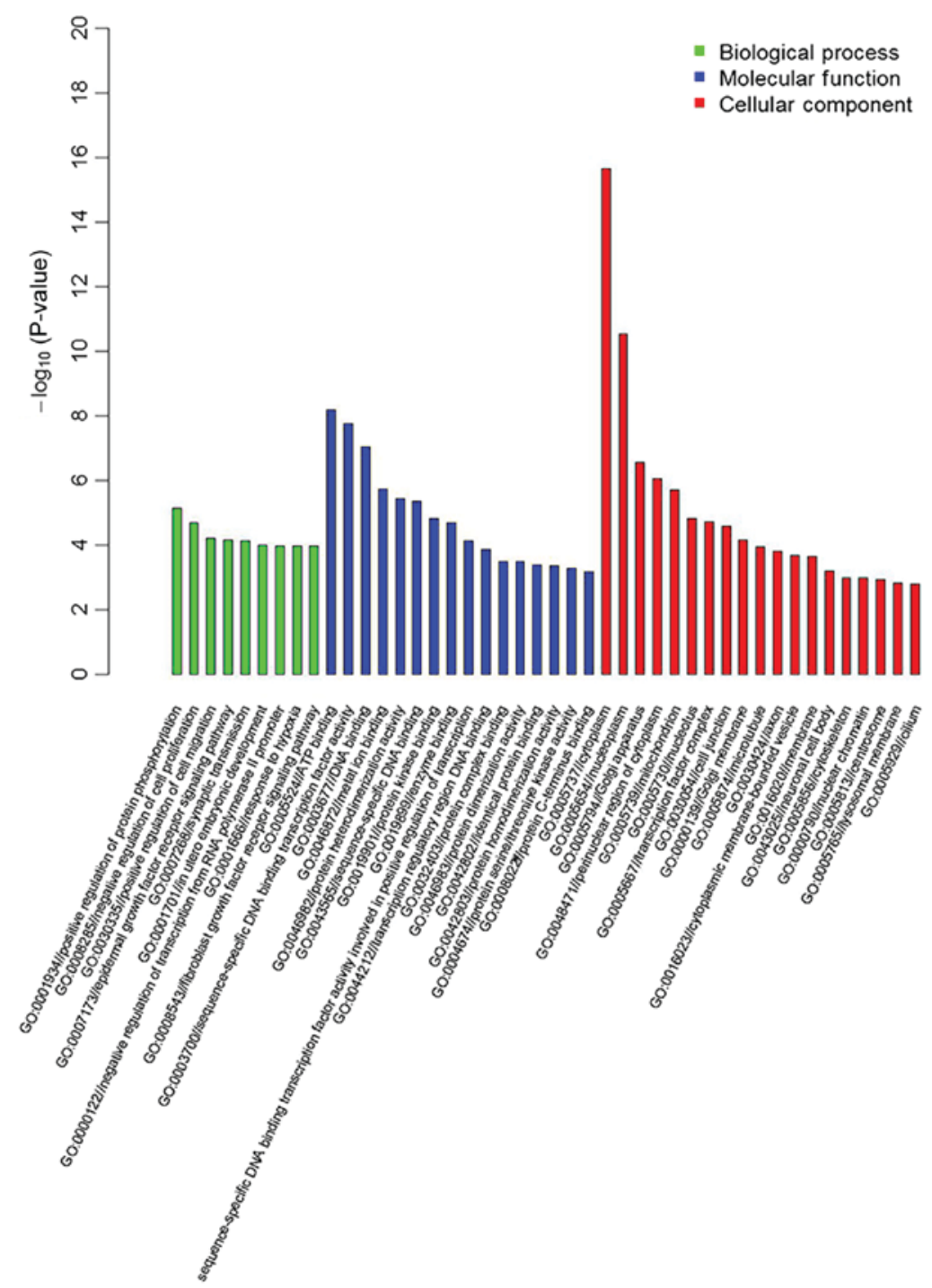

Figure 4. GO enrichment analysis of all of the differentially methylated genes. Green bars indicate 'biological process, blue bars indicate 'molecular function', and red bars indicate 'cellular component'. GO, Gene Ontology. 
Table VI. Significant differentially methylated regions.

\begin{tabular}{lcc}
\hline DMRs & $\begin{array}{c}\text { Significantly } \\
\text { hypermethylated } \\
\text { sites (n) }\end{array}$ & $\begin{array}{c}\text { Significantly } \\
\text { hypermethylated } \\
\text { sites (n) }\end{array}$ \\
\hline cDMRs & 64 & 30 \\
Island & 16 & 4 \\
Shores & 36 & 18 \\
Shelves & 5 & 3 \\
Open sea & 7 & 5 \\
rDMRs & 125 & 74 \\
Island & 38 & 13 \\
Shores & 70 & 50 \\
Shelves & 7 & 3 \\
Open sea & 10 & 8 \\
DMRs & 201 & 104 \\
Island & 179 & 70 \\
Shores & 13 & 21 \\
Shelves & 3 & 0 \\
Open sea & 6 & 13 \\
Total & 390 & 208 \\
& &
\end{tabular}

DMRs, differentially methylated regions; cDMRs, cancer-specific-DMRs; rDMRs, reprogramming-specific-DMRs.

associated with 'cellular component', and the most enriched groups included the nucleus, cytoplasm and cytosol (Fig. 4). The top 20 significant differentially methylated genes obtained from GO enrichment analysis are listed in Table VII.

KEGG Pathway-based analyses revealed that 43 signaling pathways involved 5,195 differentially methylated genes, and these genes were significantly enriched in specific pathways, including the cancer, metabolic, mitogen-activated protein kinase (MAPK), calcium, Wnt, hepatitis C, Erb-B2 receptor tyrosine kinase (ErbB), transforming growth factor (TGF)- $\beta$, vascular endothelial growth factor (VEGF), p53 and Notch signaling pathways (Table VIII).

\section{Discussion}

DNA methylation is the main epigenetic modification and regulator of gene expression in humans. Aberrant changes in genomic methylation patterns have been observed in many cancer cell lines; these are regarded as the major type of molecular aberration in malignancies $(7,8)$. Previous studies have evaluated aberrant DNA methylation in HCC by analyzing tumor tissues and adjacent non-tumor tissues (14,21-23). Their main aims were to identify novel potential biomarkers for the diagnosis of HCC or to study the associations between methylation and cirrhosis-associated HCC; the study design and enrolment criteria differed when selecting various patients for study. In addition, variations in ethnicity and the effects of the cutting edge of adjacent non-tumor tissues may lead to differing results observed across the different studies. Although previous studies have indicated a few novel DNA methylation markers that are associated with HCC, specific
DNA methylation patterns associated with the progression of HCC and alterations in methylation between HCC and normal liver cells have yet to be identified. In the present study, Illumina Infinium HumanMethylation 450K BeadChip was used to identify global DNA methylation profiles in Huh7 and L02 cells.

In the present study, a total of 102,254 differentially methylated $\mathrm{CpG}$ sites were detected across the whole-genome of Huh7 and L02 cells; more hypermethylated CpG sites $(62,702 ; 61.3 \%)$ were observed than hypomethylated $(39,552$; $38.7 \%$ ) CpG sites. The results indicated that within Huh7 cells, aberrant DNA methylation was a very common event and that hypermethylation of $\mathrm{CpG}$ sites occurred more frequently than hypomethylation. In addition, stringent criteria were employed to select the significantly differentially methylated $\mathrm{CpG}$ sites, genes and DMRs. Finally, 5,285 (66.5\%) significantly hypermethylated and 2,659 (33.5\%) hypomethylated CpG sites were identified. It has been reported that, in many types of diseases including cancers, aberrant DNA methylation is a common event, particularly aberrant DNA methylation of $\mathrm{CpG}$ islands or within promoter regions, which are associated with tumor suppressor gene inactivation or oncogene activation (16). The results of the present study indicated that within a $\mathrm{CpG}$ island, a greater number of significantly hypermethylated $\mathrm{CpG}$ sites $(1,544)$ were observed than significantly hypomethylated CpG sites $(1,201)$. This result is consistent with previous HCC genome-wide methylation studies (14,24-27). Yates et al (18) and Dudziec et al (19) demonstrated that aberrant DNA methylation occurs in $\mathrm{CpG}$ islands, but can also be detected in the regions adjacent to $\mathrm{CpG}$ islands, $\mathrm{CpG}$ shores and $\mathrm{CpG}$ shelves (15), and may lead to tumorigenesis $(20,28,29)$. The present study also demonstrated these points; significantly hypermethylated $\mathrm{CpG}$ sites in the $\mathrm{CpG}$ shores regions were more abundant than significantly hypomethylated $\mathrm{CpG}$ sites (1,137 to 632). In addition, in the $\mathrm{CpG}$ shelf regions, the significantly hypermethylated $\mathrm{CpG}$ sites were more frequent than significantly hypomethylated CpG sites (655 to 133).

DMRs are stretches of DNA in the genome. Varied DNA methylation patterns are seen between different organisms, and adjacent sites or a group of sites in proximity to each other tend to have different methylation patterns between different diseases (30). DMRs are associated with many diseases including several types of cancer (31). There are also many types of DMRs: Tissue-specific DMRs, cDMRs, rDMRs, imprinting-specific DMRs and aging-specific DMRs (20). In the present study, there were 390 differentially hypermethylated $\mathrm{CpG}$ sites located within DMRs, 233 $(59.7 \%)$ were in island regions, 119 (30.5\%) were in shore regions, and $15(3.8 \%)$ were in shelf regions. In addition, there were 208 differentially hypomethylated $\mathrm{CpG}$ sites located within DMRs, 87 (41.8\%) were in $\mathrm{CpG}$ island regions, $89(42.8 \%)$ were in shore regions and $6(2.9 \%)$ were in shelf regions. These results indicated that within HCC cells, aberrant DNA methylation may occur within $\mathrm{CpG}$ shore regions, which can also cause DNA transcriptional silencing and inactivation of gene function. Hepatocarcinogenesis was also associated with genomic instability and inactivation of gene function; the results of the present study concerning DMRs suggests that aberrant methylation within these sites may be an important epigenetic mechanism associated with 
Table VII. Top 20 significant differentially methylated genes in Gene Ontology enrichment.

\begin{tabular}{|c|c|c|}
\hline GO enrichment & $\begin{array}{c}\text { Top } 20 \text { significantly } \\
\text { hypermethylated genes in } \\
\text { GO enrichment }\end{array}$ & $\begin{array}{l}\text { Top } 20 \text { significantly } \\
\text { hypomethylated } \\
\text { genes in GO enrichment }\end{array}$ \\
\hline \multicolumn{3}{|l|}{ Biological process } \\
\hline Positive regulation of protein phosphorylation & ERBB4 & - \\
\hline Negative regulation of cell proliferation & ERBB4 & - \\
\hline $\begin{array}{l}\text { Epidermal growth factor receptor signaling } \\
\text { pathway }\end{array}$ & ERBB4 & - \\
\hline Synaptic transmission & PCDH8 & - \\
\hline $\begin{array}{l}\text { Negative regulation of transcription from RNA } \\
\text { polymerase II promoter }\end{array}$ & $\begin{array}{l}\text { SALL4; NKX6-2; } \\
\text { MEIS2; TCF21; ZBTB32; }\end{array}$ & - \\
\hline $\begin{array}{l}\text { Fibroblast growth factor receptor signaling } \\
\text { pathway }\end{array}$ & ERBB4 & - \\
\hline \multicolumn{3}{|l|}{ Molecular function } \\
\hline Protein binding & $\begin{array}{l}\text { ERBB4; PAX6; BCL3; DOCK1; } \\
\text { ZBTB32; BCL2 }\end{array}$ & $\begin{array}{l}\text { PLXND1; LASP1; MMP9; DKK1; } \\
\text { DNAJB1; RB1; GAS1; AHCYL1 }\end{array}$ \\
\hline ATP binding & ERBB4 & - \\
\hline $\begin{array}{l}\text { Sequence-specific DNA binding transcription } \\
\text { factor activity }\end{array}$ & PAX6; NKX6-2; BCL3 & SIX2; RB1 \\
\hline DNA binding & PAX6; SALL4; BCL3; ZIC4; ZBTB32 & PRDM8; RB1 \\
\hline Metal ion binding & SALL4; ZIC4; ZBTB3 & PRDM8; ARSG; NPTX1 \\
\hline Protein heterodimerization activity & BCL2 & NPR3; SDCBP2 \\
\hline Sequence-specific DNA binding & BCL2 & SIX2 \\
\hline Protein kinase binding & PAX6 & - \\
\hline Transcription regulatory region DNA binding & ERBB4; TCF21 & - \\
\hline Protein complex binding & - & SIX2 \\
\hline Protein dimerization activity & TCF21 & - \\
\hline Identical protein binding & BCL2 & MMP9; RB1 \\
\hline Protein homodimerization activity & ERBB4; BCL2 & SDCBP2 \\
\hline Protein C-terminus binding & - & SDCBP2 \\
\hline \multicolumn{3}{|l|}{ Cellular component } \\
\hline Nucleus & $\begin{array}{l}\text { ERBB4; PAX6; SALL4; NKX6-2; } \\
\text { BCL3; DOCK1; MEIS2; ZIC4; TCF21; } \\
\text { ZBTB32; BCL2 }\end{array}$ & PRDM8; SIX2; RB1 \\
\hline Cytosol & ERBB4 & - \\
\hline Cytoplasm & $\begin{array}{l}\text { ERBB4; PAX6; SALL4; BCL3; } \\
\text { DOCK1; BCL2; BDNF }\end{array}$ & SDCBP2; DNAJB1 \\
\hline Nucleoplasm & ERBB4; ZBTB32 & RB1 \\
\hline Golgi apparatus & - & STC2 \\
\hline Perinuclear region of cytoplasm & BCL3; BDNF & NPTX1 \\
\hline Mitochondrion & ERBB4; BCL2 & SLC25A42 \\
\hline Nucleolus & ERBB4; PAX6 & DNAJB1; RB1 \\
\hline Transcription factor complex & LRFN2 & - \\
\hline Cell junction & $\mathrm{PCDH}$ & - \\
\hline Membrane & ERBB4; DOCK1; BCL2 & SLC16A6 \\
\hline Nuclear chromatin & PAX6 & - \\
\hline
\end{tabular}

GO, Gene Ontology.

hepatocarcinogenesis. These results may provide more information regarding the associations between $\mathrm{HCC}$ and aberrant DNA methylation.
Furthermore, the present study listed the top 20 significantly hyper- and hypo-methylated $\mathrm{CpG}$ sites, and genes in DMRs within Huh7 cells compared with L02 cells. The top 20 
Table VIII. Kyoto encyclopedia of genes and genomes pathway analysis of differentially methylated genes.

Number of differentially

Pathway methylated genes (n)

\begin{tabular}{lr}
\hline Pathways in cancer & 309 \\
Focal adhesion & 186 \\
MAPK signaling pathway & 251 \\
Wnt signaling pathway & 143 \\
Axon guidance & 120 \\
TGF- $\beta$ signaling pathway & 81 \\
Basal cell carcinoma & 55 \\
Regulation of actin cytoskeleton & 191 \\
Colorectal cancer & 61 \\
Adherens junction & 71 \\
Chronic myeloid leukemia & 71 \\
ECM-receptor interaction & 81 \\
Endocytosis & 186 \\
Pyrimidine metabolism & 97 \\
Non-small cell lung cancer & 57 \\
Hedgehog signaling pathway & 54 \\
Neurotrophin signaling pathway & 116 \\
Glioma & 63 \\
Endometrial cancer & 52 \\
VEGF signaling pathway & 71 \\
ErbB signaling pathway & 80 \\
Small cell lung cancer & 80 \\
Lysosome & 110 \\
Metabolic pathways & 964 \\
Calcium signaling pathway & 159 \\
Purine metabolism & 150 \\
Ubiquitin mediated proteolysis & 128 \\
Insulin signaling pathway & 128 \\
Notch signaling pathway & 45 \\
Protein processing in endoplasmic reticulum & 156 \\
RNA polymerase & 32 \\
Hepatitis C & 116 \\
Renal cell carcinoma & 61 \\
Aminoacyl-tRNA biosynthesis & 42 \\
B cell receptor signaling pathway & 69 \\
Thyroid cancer & 29 \\
Melanoma & 65 \\
Oocyte meiosis & 103 \\
Adipocytokine signaling pathway & 64 \\
Melanogenesis & 94 \\
Vascular smooth muscle contraction & 115 \\
Selenocompound metabolism & 26 \\
p53 signaling pathway & 63 \\
\hline
\end{tabular}

significantly hypermethylated genes, which were high-ranking with notable differences in the absolute value of $\beta$-difference, included the following: ERBB4, paired box 6, splat like transcription factor 4, protocadherin (PCDH)-8, NK2 homeobox 6, B-cell lymphoma (BCL)-3, glypican 6 , family with sequence similarity 196 member A, dedicator of cytokinesis 1, Meis homeobox 2, Zic family member 4 , transcription factor 21 , zinc finger and BTB domain containing 32 , leucine rich repeat and fibronectin type III domain containing 2, BCL2, PCDH9, DPY30 domain-containing protein 2, zinc finger CCHC-type containing 24, brain-derived neurotrophic factor, cg00057722 and cg08640046. The functional role of these genes in HCC requires further study. The top 20 significant differentially hyper- and hypo-methylated genes from GO enrichment were also listed. These genes, which were located within DMRs, were mainly associated with 'cell differentiation development', 'transcription factor activity', 'sequence-specific DNA binding', 'cellular development process' and 'cell junction'.

Additionally, through GO enrichment analysis, the present study revealed that aberrant DNA methylation in HCC was associated with cell differentiation and proliferation, and through KEGG pathway analysis, 43 signaling pathways associated with HCC were identified, including pathways in cancer, MAPK signaling, Wnt signaling, VEGF signaling and p53 signaling pathways. Previous studies have demonstrated that aberrant DNA hypermethylation can downregulate the expression of cell cycle inhibitors, $\mathrm{p} 16^{\mathrm{INK} 4 \mathrm{~A}}, \mathrm{p} 53$ and factors involved in TGF- $\beta$ /mothers against decapentaplegic signaling $(32,33)$. Thus far, researchers have revealed that the inactivation of Wnt pathway-associated antagonists is linked to the aberrant DNA hypermethylation of some genes $(34,35)$. Activation of the ERB receptor and MAPK signaling pathways, as well as the regulation of epigenetic proteins that were previously demonstrated to promote cancer growth and metastasis, have been reported to be possible candidate targets for anticancer treatment in multiple types of cancer, including $\mathrm{HCC}(32,36)$.

In addition, HCC cells may escape or become tolerant to chemotherapy via various mechanisms, therefore, identifying novel drugs is very important for the future therapy of HCC. The application of inhibitors of DNA methylated drugs in the treatment of cancer has gradually attracted the attention of researchers (37), including 5-azacytidine (5-aza-C), decitabine (5-aza-2'-deoxycytidine, 5-aza-dC), 1- $\beta$-D-arabinofuranosyl-5azacytosine, dihydro-5-azacytosine (38), SGI-110 (previously known as S110), a dinucleotide of 5-aza-2'-deoxycytidine and deoxyguanosine, containing 5-azaCdR moiety, which has been revealed to be very effective in inhibiting DNA methylation, though its stability and cytotoxicity are comparable to that of decitabine (39), and a non-nucleoside DNA methyltransferase inhibitor, SGI-1027 $(40,41)$. To the best of our knowledge, there have been only a few studies investigating the effects of demethylation agents on $\mathrm{HCC}$ in vitro.

In conclusion, the present study detected genome-wide DNA methylation patterns occurring in Huh7 cells, and identified numerous differentially hypo- and hypermethylated $\mathrm{CpG}$ sites, genes, DMRs and signaling pathways associated with HCC. Additionally, the diversity in methylation within Huh7 cells was also observed. The results of the present study may provide important information regarding the molecular mechanisms underlying methylation in Huh7 cells, which may be useful in future research into the underlying mechanisms associated with HCC. In addition, HCC cells may escape or develop tolerance to chemotherapy via various mechanisms, therefore, identifying novel drugs is very important for future therapies of HCC. The application of inhibitors of DNA methylation for the treatment of cancer has gradually attracted more attention within the field (37), 
and there have been a few studies investigating the effects of demethylation agents in HCC in vitro. The results of the present study may provide a useful basis for future research into effective HCC therapies.

\section{Acknowledgements}

Not applicable.

\section{Funding}

The present study was supported by The Science and Technology project of Shenyang (grant no. F13-212-9-00).

\section{Availability of data and materials}

The analyzed datasets generated during this study are available from the corresponding author on reasonable request.

\section{Authors' contributions}

JZ conceived and designed the study. NS, CZ, YS, BZ and BC performed the experiments. NS and AJ analyzed the data. NS wrote the manuscript.

\section{Ethics approval and consent to participate}

Not applicable.

\section{Patient consent for publication}

Not applicable.

\section{Competing interests}

The authors declare that they have no competing interests.

\section{References}

1. Torre LA, Bray F, Siegel RL, Ferlay J, Lortet-Tieulent J and Jemal A: Global cancer statistics, 2012. CA Cancer J Clin 65: 87-108, 2015.

2. Zuo TT, Zheng RS, Zhang SW, Zeng HM and Chen WQ: Incidence and mortality of liver cancer in China in 2011. Chin J Cancer 34: 56, 2015.

3. Chen W, Zheng R, Baade PD, Zhang S, Zeng H, Bray F, Jemal A, Yu XQ and He J: Cancer statistics in China, 2015. CA Cancer J Clin 66: 115-132, 2016.

4. Tanaka M, Katayama F, Kato H, Tanaka H, Wang J, Qiao YL and Inoue $\mathrm{M}$ : Hepatitis $\mathrm{B}$ and $\mathrm{C}$ virus infection and hepatocellular carcinoma in China: A review of epidemiology and control measures. J Epidemiol 21: 401-416, 2011.

5. Panayiotidis MI: Cancer epigenetics as biomarkers of clinical significance. Cancer Lett 342: 168-169, 2014

6. Udali S, Guarini P, Moruzzi S, Ruzzenente A, Tammen SA, Guglielmi A, Conci S, Pattini P, Olivieri O, Corrocher R, et al: Global DNA methylation and hydroxymethylation differ in hepatocellular carcinoma and cholangiocarcinoma and relate to survival rate. Hepatology 62: 496-504, 2015.

7. Jones PA and Takai D: The role of DNA methylation in mammalian epigenetics. Science 293: 1068-1070, 2001.

8. Esteller M: Epigenetics in cancer. N Engl J Med 358: 1148-1159, 2008.

9. Jain S, Xie L, Boldbaatar B, Lin SY, Hamilton JP, Meltzer SJ, Chen SH, Hu CT, Block TM, Song W and Su YH: Differential methylation of the promoter and first exon of the RASSF1A gene in hepatocarcinogenesis. Hepatol Res 45: 110-123, 2015.
10. Hinrichsen I, Kemp M, Peveling-Oberhag J, Passmann S, Plotz G, Zeuzem S and Brieger A: Promoter methylation of MLH1, PMS2, $\mathrm{MSH} 2$ and p16 is a phenomenon of advanced-stage HCCs. PLoS One 9: e84453, 2014.

11. Xu B, Nie Y, Liu X, Feng S, Yang Z, Wang Z, Zheng Q and Luo X: Quantitative analysis of APC promoter methylation in hepatocellular carcinoma and its prognostic implications. Oncol Lett 7: 1683-1688, 2014.

12. Jain S, Chen S, Chang KC, Lin YJ, Hu CT, Boldbaatar B, Hamilton JP, Lin SY, Chang TT, Chen SH, et al: Impact of the location of CpG methylation within the GSTP1 gene on its specificity as a DNA marker for hepatocellular carcinoma. PLoS One 7: e35789, 2012.

13. Qu Z, Jiang Y, Li H, Yu DC and Ding YT: Detecting abnormal methylation of tumor suppressor genes GSTP1, P16, RIZ1, and RASSF1A in hepatocellular carcinoma and its clinical significance. Oncol Lett 10: 2553-2558, 2015.

14. Shen J, Wang S, Zhang YJ, Wu HC, Kibriya MG, Jasmine F, Ahsan H, Wu DP, Siegel AB, Remotti H and Santella RM: Exploring genome-wide DNA methylation profiles altered in hepatocellular carcinoma using Infinium HumanMethylation 450 BeadChips. Epigenetics 8: 34-43, 2013.

15. Bibikova M, Barnes B, Tsan C, Ho V, Klotzle B, Le JM, Delano D, Zhang L, Schroth GP, Gunderson KL, et al: High density DNA methylation array with single $\mathrm{CpG}$ site resolution. Genomics 98: 288-295, 2011.

16. Esteller M: Epigenetic gene silencing in cancer: The DNA hypermethylome. Hum Mol Genet 16: R50-R59, 2007.

17. Herman JG and Baylin SB: Gene silencing in cancer in association with promoter hypermethylation. N Engl J Med 349: 2042-2054, 2003.

18. Yates DR, Rehman I, Meuth M, Cross SS, Hamdy FC and Catto JW: Methylational urinalysis: A prospective study of bladder cancer patients and age stratified benign controls. Oncogene 25: 1984-1988, 2006.

19. Dudziec E, Miah S, Choudhry HM, Owen HC, Blizard S, Glover M, Hamdy FC and Catto JW: Hypermethylation of CpG islands and shores around specific microRNAs and mirtrons is associated with the phenotype and presence of bladder cancer. Clin Cancer Res 17: 1287-1296, 2011.

20. Irizarry RA, Ladd-Acosta C, Wen B, Wu Z, Montano C, Onyango P, Cui H, Gabo K, Rongione M, Webster M, et al: The human colon cancer methylome shows similar hypo- and hypermethylation at conserved tissue-specific $\mathrm{CpG}$ island shores. Nat Genet 41: 178-186, 2009.

21. Nishida N, Kudo M, Nagasaka T, Ikai I and Goel A: Characteristic patterns of altered DNA methylation predict emergence of human hepatocellular carcinoma. Hepatology 56: 994-1003, 2012.

22. Shen J, Wang S, Zhang YJ, Kappil M, Wu HC, Kibriya MG, Wang Q, Jasmine F, Ahsan H, Lee PH, et al: Genome-wide DNA methylation profiles in hepatocellular carcinoma. Hepatology 55: 1799-1808, 2012

23. Udali S, Guarini P, Ruzzenente A, Ferrarini A, Guglielmi A, Lotto V, Tononi P, Pattini P, Moruzzi S, Campagnaro T, et al: DNA methylation and gene expression profiles show novel regulatory pathways in hepatocellular carcinoma. Clin Epigenetics 7: 43, 2015.

24. Gao W, Kondo Y, Shen L, Shimizu Y, Sano T, Yamao K, Natsume A, Goto Y, Ito M, Murakami H, et al: Variable DNA methylation patterns associated with progression of disease in hepatocellular carcinomas. Carcinogenesis 29: 1901-1910, 2008.

25. Shin SH, Kim BH, Jang JJ, Suh KS and Kang GH: Identification of novel methylation markers in hepatocellular carcinoma using a methylation array. J Korean Med Sci 25: 1152-1159, 2010.

26. Ammerpohl O, Pratschke J, Schafmayer C, et al: Distinct DNA methylation patterns in cirrhotic liver and hepatocellular carcinoma. Int J Cancer 130: 1319-1328, 2012.

27. Kohles N, Nagel D, Jüngst D, Durner J, Stieber P and Holdenrieder S: Prognostic relevance of oncological serum biomarkers in liver cancer patients undergoing transarterial chemoembolization therapy. Tumour Biol 33: 33-40, 2012.

28. Doi A, Park IH, Wen B, Murakami P, Aryee MJ, Irizarry R, Herb B, Ladd-Acosta C, Rho J, Loewer S, et al: Differential methylation of tissue- and cancer-specific $\mathrm{CpG}$ island shores distinguishes human induced pluripotent stem cells, embryonic stem cells and fibroblasts. Nat Genet 41: 1350-1353, 2009.

29. Ogoshi K, Hashimoto S, Nakatani Y, Qu W, Oshima K, Tokunaga K, Sugano S, Hattori M, Morishita S and Matsushima K: Genome-wide profiling of DNA methylation in human cancer cells. Genomics 98: 280-287, 2011. 
30. Rakyan VK, Down TA, Balding DJ and Beck S: Epigenome-wide association studies for common human diseases. Nat Rev Genet 12: 529-541, 2011.

31. Weber M, Davies JJ, Wittig D, Oakeley EJ, Haase M, Lam WL and Schübeler D: Chromosome-wide and promoter-specific analyses identify sites of differential DNA methylation in normal and transformed human cells. Nat Genet 37: 853-862, 2005.

32. Calvisi DF, Pascale RM and Feo F: Dissection of signal transduction pathways as a tool for the development of targeted therapies of hepatocellular carcinoma. Rev Recent Clin Trials 2: 217-236, 2007.

33. Kuo KK, Jian SF, Li YJ, Wan SW, Weng CC, Fang K, Wu DC and Cheng KH: Epigenetic inactivation of transforming growth factor-beta1 target gene HEYL, a novel tumor suppressor, is involved in the P53-induced apoptotic pathway in hepatocellular carcinoma. Hepatol Res 45: 782-793, 2015.

34. Umer M, Qureshi SA, Hashmi ZY, Raza A, Ahmad J, Rahman M and Iqbal M: Promoter hypermethylation of Wnt pathway inhibitors in hepatitis C virus-induced multistep hepatocarcinogenesis. Virol J 11: 117, 2014.

35. Ding SL, Yang ZW, Wang J, Zhang XL, Chen XM and Lu FM: Integrative analysis of aberrant Wnt signaling in hepatitis $\mathrm{B}$ virus-related hepatocellular carcinoma. World J Gastroenterol 21: $6317-6328,2015$
36. Stefanska B, Cheishvili D, Suderman M, Arakelian A, Huang J Hallett M, Han ZG, Al-Mahtab M, Akbar SM, Khan WA, et al: Genome-wide study of hypomethylated and induced genes in patients with liver cancer unravels novel anticancer targets. Clin Cancer Res 20: 3118-3132, 2014.

37. Yan W, Herman JG and Guo M: Epigenome-based personalized medicine in human cancer. Epigenomics 8: 119-133, 2016.

38. Ghoshal K and Bai S: DNA methyltransferases as targets for cancer therapy. Drugs Today (Barc) 43: 395-422, 2007.

39. Yoo CB, Jeong S, Egger G, Liang G, Phiasivongsa P, Tang C, Redkar S and Jones PA: Delivery of 5-aza-2'-deoxycytidine to cells using oligodeoxynucleotides. Cancer Res 67: 6400-6408, 2007.

40. Datta J, Ghoshal K, Denny WA, Gamage SA, Brooke DG, Phiasivongsa P, Redkar S and Jacob ST: A new class of quinoline-based DNA hypomethylating agents reactivates tumor suppressor genes by blocking DNA methyltransferase 1 activity and inducing its degradation. Cancer Res 69: 4277-4285, 2009.

41. Gros C, Fleury L, Nahoum V, Faux C, Valente S, Labella D, Cantagrel F, Rilova E, Bouhlel MA, David-Cordonnier MH, et al: New insights on the mechanism of quinoline-based DNA Methyltransferase inhibitors. J Biol Chem 290: 6293-6302, 2015.

(7) (5) This work is licensed under a Creative Commons Attribution 4.0 International (CC BY-NC 4.0) License 